\title{
Deformation analysis based on GNSS measurements in Tashkent region
}

\author{
Dilbarkhon Sh. Fazilova ${ }^{*}$, and Lola V. Sichugova ${ }^{1}$ \\ ${ }^{1}$ Astronomical Institute of Uzbek Academy of Sciences, 100052, Astronomicheskaya 33, Tashkent, \\ Uzbekistan
}

\begin{abstract}
This paper presents the results of the GNSS geodetic network deformation analysis in the Tashkent region, as an example of an urban area, where obtaining reliable information for assessing hazard risk is of great importance. A software package in Delphi language has been developed for the assessment of the datum differences between 2009 and 2011 by implementing the 3D Helmert transformation method. The result revealed that there is significant translation and rotation in the network, while the scale of the network remains almost constant during two years period. The area strain was estimated by the finite element method. Most of the Tashkent region can be considered to be in a high compression (negative dilatation) strain state with maximum value $-230 \times 10^{-8}$. On the contrary, remarkable positive dilatation strain is concentrated on the coastline of the Charvak water reservoir, where large strain is about $351 \times 10^{-8}$.
\end{abstract}

Keywords. GNSS network, strain accumulation, finite element method.

\section{Introduction}

Tashkent region is located in the Middle Tien-Shan zone at the boundary two large components. It is a part of the post-platform mobile region and is located in the transition zone between the Tien-Shan orogenic territory and the Turan plate. The mountain ranges (Karzhantau, Chatkal and Kurami), covered by young structures in some areas, surround this field and decrease in southwest direction. Recent up thrusts and deflections characterize plain part of the territory $[1,2]$. According the results are presented in map of Peak Ground Acceleration, the region belongs one of the two fields in the country of very high seismic activity (up to $4.8 \mathrm{~m} / \mathrm{s}^{2}$ ) [3]. The magnitude of the maximum ground velocity must exceed values for 50 years $50 \mathrm{~cm} / \mathrm{s}$ with probability $\mathrm{P}=0.99$ according the analysis the velocity graphs of $M=3.8-6.2$ earthquakes [4]. Significant velocity rates between $30 \mathrm{~mm} /$ year and $60 \mathrm{~mm} /$ year were found to the tectonic fault zones and mountainous part of the area, the flat, foothills zones show velocity rate up to $15 \mathrm{~mm}$ / year [5]. Charvak water reservoir with area around $40 \mathrm{~km}^{2}$ and with the volume of 2 billion $\mathrm{m}$ was constructed for hydropower generating, irrigation purpose and for controlling river flow. In 1970, construction of the

\footnotetext{
*Corresponding author: dil_faz@yahoo.com
} 
Charvak dam with the height of $167 \mathrm{~m}$ has ended and started flowage of Brichmulla depression and filling of the Charvak reservoir [6].

The GNSS geodetic network includes 31 stations (fig. 1), collected in campaign mode between 2009 and 2011 by researchers from the Institute of Seismology and the National Center of Geodesy and Cartography to study the modern deformations of the Earth's surface using space geodetic methods.

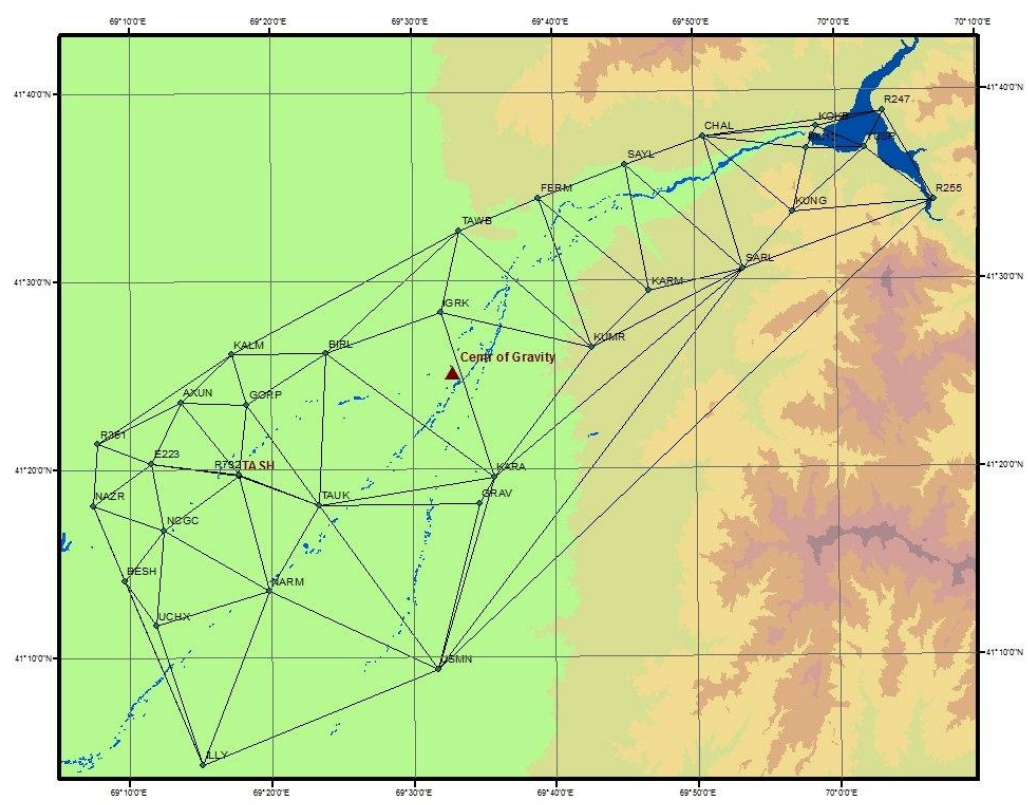

Fig.1. GNSS network of study area

The region is well studied in terms of seismic activity and therefore a geodetic network was established here. The main task was to conduct research on the station's velocities, deformations based on long-term GNSS measurements. The data were to become the basis for constructing a geodynamic model of the region's microplates. However, after 2011 measurements were not taken due to both financial and organizational limitations. Therefore, in this work, we only consider the stability of the network, horizontal and vertical displacements caused by the influence of various datums. Stations installed with different spacing and varies from $5 \mathrm{~km}$ to $20 \mathrm{~km}$. The GNSS data were observed over 6 time periods (04.09.2009 - 27.09.2009; 05.11.2009 - 02.12.2009; 25.04.2010 06.06.2010; 17.10.2010 - 6.11.2010; 19.04.2011 - 10.05.2011; 20.09.2011 - 6.11.2011) with the observation rate $10 \mathrm{~s}$. Session duration for each station was 3 days. Ashtech ZSurveyor dual-frequency receivers and ASH 701975-01 antennas were applied in all the surveys. Observations were carried out simultaneously by 12 receivers, and 6 were in stationary mode. Site positions and baselines for each epoch were estimated by aforementioned organizations with Trimble Total Control (TTC) software version 2.73.

The free network solution was introduced for each campaign. For mathematical processing of satellite measurements, at least one point must be connected to a point on the international geodynamic network. Therefore, the absolute coordinates of the initial point NCGC were preliminary calculated relative to the international station TASH. Additionally, to tie the regional measurements to the global reference frame ITRF2008, data from continuously operating IGS permanent network stations (KIT3, MDVJ, POL2, 
NSSP) were used. Coordinates of the test network estimated by six solutions have both different epochs and different datum. For accurate calculation of station displacement vectors, it is necessary to take into account the measurement errors that arise as a result of the choice of the reference system. As a result, "rotation" and "deformation" of the network arise. To eliminate the effect of visible "rotation" and "deformations" it is recommended to use the transformation methods. This study was aimed to compare the coordinate difference between the campaign's epochs and referencing them into the first epoch of measurements by using 3D Helmert transformation method for the possibility of an accurate assessment of network deformations and strain accumulation computation.

\section{Materials and methods}

\subsection{Datum investigation with 3-D Helmert transformation}

Usually, the processing of geodetic measurements to identify modern movements of the earth's crust is performed on relatively stable geological structures. However, for the study area, there is not yet a sufficiently accurate tectonic model and, accordingly, there is no sure confirmation that the points will remain stable. The territory of the Tashkent region is subject not only to modern tectonic movements, but also a change in the water level in the Charvak reservoir can be the cause of the induced disturbances of the Earth's surface. One of the solutions to the problem is the implementation in network processing of continuously working stations, for example IGS data. Taking into account that our network was processed relative to several high-precision stations of the IGS, in this study, all 31 points were used to perform the transformation procedure. Another reason was to look at how and where there will be more horizontal movement for further redefinition of the regional tectonic model.

The network adjustment error is usually influenced by two factors: orientation and scale of the network. Therefore, a 7-parameter transformation method was chosen in the work to analyze deformation between two epochs and strain parameters in the geodetic network, three-dimensional conformal (it preserves shapes of objects) coordinate transformation is also known as seven-parameter similarity transformation was applied. It converts separate surveys into a common reference coordinate system and it can be thought of as a three-step process: scaling, rotation and translation. The seven parameters of the transformation between convertible $(x, y)$ and reference $(X, Y)$ systems (epochs) - one scaling $(m)$, three rotations $\left(R_{X}, R_{Y}, R_{Z}\right)$ and three rotations translations $\left(T_{X}, T_{Y}, T_{Z}\right)$ can be determined uniquely with the minimum of three common points for both systems $[7,8]$ :

$$
\left[\begin{array}{c}
X \\
Y \\
Z
\end{array}\right]_{i}=\left[\begin{array}{l}
T_{X} \\
T_{Y} \\
T_{Z}
\end{array}\right]+(1+m)\left[\begin{array}{ccc}
1 & -R_{Z} & R_{Y} \\
R_{Z} & 1 & -R_{X} \\
-R_{Y} & R_{X} & 1
\end{array}\right]\left[\begin{array}{l}
x \\
y \\
z
\end{array}\right]_{i}
$$

When more than three stations are present, the solution is obtained by the conventional least square adjustment procedure and the equations system can be written in the matrix form:

$$
A_{i} d p=L+V
$$

Where $L$-coordinate difference, $V$-vector of residuals. The design matrix $A_{i}$ for station $i$ of the are defined as 


$$
A_{i}=\left[\begin{array}{cccccccccccc}
1 & 0 & 0 & x_{i} & 0 & 0 & y & z & 0 & 0 & z & -y \\
0 & 1 & 0 & 0 & y & 0 & x & 0 & z & -z & 0 & x \\
0 & 0 & 1 & 0 & 0 & z & 0 & x & y & y & -x & 0
\end{array}\right]
$$

The adjustment of the slightly overdetermined system (2) via normal equations yields the parameter vector $d p$ of unknown transformation parameters (scaling, three rotations and three rotations translations) $d p=\left[\begin{array}{ll}d T_{x} & d T_{y} d T_{z} d m d \omega_{x} d \omega_{y} d \omega_{z}\end{array}\right]^{T}$

$$
d p=\left(A^{T} A\right)^{-1} A^{T} L
$$

Once parameters of the transformation are determined, the coordinates $(x, y, z)$ are transformed to new $(X, Y, Z)^{\prime}$ coordinate system using eq. (1). The coordinate values for all sessions were transformed to the topocentric coordinate system $(\mathrm{E}, \mathrm{N}, \mathrm{U})$ :

$$
\left[\begin{array}{l}
E_{n} \\
N_{n} \\
U_{n}
\end{array}\right]=\left[\begin{array}{ccc}
-\sin L_{0} & \cos L_{0} & 0 \\
-\sin B_{0} \cos L_{0} & -\sin B_{0} \sin L_{0} & \cos B_{0} \\
\cos B_{0} \cos L_{0} & \cos B_{0} \sin L_{0} & \sin B_{0}
\end{array}\right]\left[\begin{array}{c}
X_{n}-X_{0} \\
Y_{n}-Y_{0} \\
Z_{n}-Z_{0}
\end{array}\right]
$$

where $\left(\mathrm{X}_{0}, \mathrm{Y}_{0}, \mathrm{Z}_{0}\right)$ and $\left(\mathrm{B}_{0}, \mathrm{~L}_{0}\right)$ are geocentric and geodetic coordinates (latitude and longitude) respectively of the center of gravity of the network ( marked as red circle on fig.1). First epoch (Sept. 2009) of the measurement was choosing as reference for further calculations and the horizontal displacement vectors of pairs first - second (Nov. 2009), first - third (June 2010), first - fourth (Nov. 2010), first - fifth (May 2011) and first -six (Nov. 2011) epochs of each GNSS monitoring station was calculated as

$$
R_{n}=\sqrt{\left(N_{n}^{\prime}-n_{n}\right)^{2}+\left(E_{n}^{\prime}-e_{n}\right)^{2}}
$$

$d U_{n}=U_{n}^{\prime}-u_{n}$ height component variations will be used for estimation of the network vertical deformation. A software package in Delphi has been developed for the assessment of the datum differences between 2009 and 2011 by implementing the 3D Helmert transformation method.

Data analysis was performed in the ArcGIS 10.1.

\subsection{Estimation of strain accumulation by finite element model}

The calculation of the network strain by the finite element method was used to assess the deformation effect. The principles and basics of finite element method are generally known and are described in numerous publications $[9,10]$. In the first step, the network has been constructed of finite elements (triangles) based on the Delaunay triangulation (Green and Sibson, 1978) (fig.1). Local strain field was computed for each triangle in the network. The strain values (E) on the earth's surface can be expressed in terms of displacements between adjacent stations at initial and final epochs $\left(l_{0}, l_{l}\right)[11]$ :

$$
E=\frac{\left|l-l_{0}\right|}{l_{0}}
$$

This equation is created for each baseline of a triangle. The coordinates of GNSS points were represented in the Mercator projection for calculating distances (radius-vectors) between the nearest stations. 
Finally, all individual results are integrated for whole investigated region by creating homogeneous surface with the nearest neighbor interpolation method. It is based on comparison of the distribution of distance $d$ between a point $x$ and the nearest neighboring points $y$ of a set of randomly distributed data [12]:

$$
d(x, y)=\|x-y\|=\sqrt{(x-y)(x-y)}=\left(\left(\sum_{i}\left(x_{i}-y_{i}\right)\right)^{2}\right)^{1 / 2}
$$

The method has been investigated and used in recent work for assessment of normal heights surface for Fergana valley territory in Uzbekistan [13]. It showed more reliable results than commonly used polynomial interpolation method for creating surface over the high mountains region.

\section{Results}

The transformation parameters translations $\left(T_{X}, T_{Y}, T_{Z}\right)$, scale $(m)$ and rotations $\left(\omega_{X}, \omega_{Y}\right.$, $\omega_{Z}$ ) between the first-reference and subsequent (from second to sixth) epochs are given in the Table 1 . The result revealed that there is significant translation and rotation in the network, while the scale of the network remains almost constant during two years period (from September 2009 to November 2011).

Table 1. The transformation parameters between different epochs of measurements

\begin{tabular}{|c|c|c|c|c|c|c|c|c|}
\hline Epochs & Period & $T_{x}, m$ & $T_{y}, m$ & $T_{z}, m$ & $m$ & $\begin{array}{c}\omega_{X}, \\
s e c\end{array}$ & $\omega_{Y}, \mathrm{sec}$ & $\omega_{Z} s e c$ \\
\hline $1-2$ & $09.2009-$ & -9.96 & 0.02 & 4.12 & 0.99 & 0.076 & -0.294 & 0.185 \\
& 12.2009 & & & & & & & \\
\hline $1-3$ & $\begin{array}{c}09.2009- \\
06.2010\end{array}$ & -5.16 & -2.04 & -1.90 & 1.00 & 0.025 & -0.028 & 0.160 \\
\hline $1-4$ & $\begin{array}{c}09.2009- \\
11.2010\end{array}$ & 2.48 & -5.53 & 6.20 & 0.99 & 0.258 & -0.006 & -0.110 \\
\hline $1-5$ & $\begin{array}{c}09.2009- \\
05.2011\end{array}$ & -6.99 & 1.35 & 9.24 & 0.99 & 0.157 & -0.295 & 0.106 \\
\hline $1-6$ & $09.2009-$ & 4.29 & 8.72 & 21.16 & 0.99 & 0.289 & -0.112 & -0.044 \\
\hline
\end{tabular}

The horizontal displacement vectors were calculated using the eq. 5 and, for a more visual representation of the deformation of the whole region, the values were interpolated over the study area (eq. 7). The presented in fig. 2a result demonstrate horizontal displacements of the network with rates between $2 \mathrm{~cm}$ and $21 \mathrm{~cm}$ during whole observation period (first and sixth epochs) from September 2009 to November 2011. Analysis of calculated displacement vectors has been carried out separately for different parts of the region. The investigated field was conditionally divided into three main parts. The first one belongs to the Charvak coastal zone (KOKB, NM12, YUSP, CHAL, KUNG, R247, R255, SAYL, SARL, KARM, FERM) and divided from the others by the Kumbel fault. The second and the third are separated from each other by the largest Karjantau depression and hereinafter called conditionally the Northern coastal zone of the Chirchik river (AXUN, BIRL, E223, GORP, IGRK, KALM, NAZR, R351, TAWB) and the Southern coastal zone of the Chirchik river (KUMR, GRAV, KARA, TAUK, R732, NARM, NCGC, BESH, UCHX, USMN, ILLY). It should be noted that deformations in the Chirchik river valley are less (about $1 \mathrm{~cm}$ ) than in the coastal part.

The stations located in Northern coastal part of the river have displacement rate from 4 $\mathrm{cm}$ to $10 \mathrm{~cm}$ and the stations located in the Southern coastal zone have a displacement rates from $2 \mathrm{~cm}$ to $17 \mathrm{~cm}$. Moreover, the stations located closely to a coastal part of the Charvak 
reservoir (R247, NM12, R255, YUSP) have a maximum displacement rates in this zone between $13 \mathrm{~cm}$ and $20 \mathrm{~cm}$. There is a tendency to rotational movement along the Kumbel and Karjantau faults (fig2a).

The presented in fig. $2 \mathrm{~b}$ result demonstrate vertical displacements of the network with rates between $-5 \mathrm{~cm}$ and $20 \mathrm{~cm}$ during the two years observation period. Station (KALM) located in this region shows relative to other stations a high rate of vertical displacement 20 $\mathrm{mm}$, the cause of which may mainly be instrumental (antenna information, et al.) errors than tectonic effects. Therefore, this station was excluded from further analysis. It can be concluded that for this region, horizontal displacements are a consequence of both tectonic and hydrological processes. While vertical deformations are the result of most tectonic phenomena

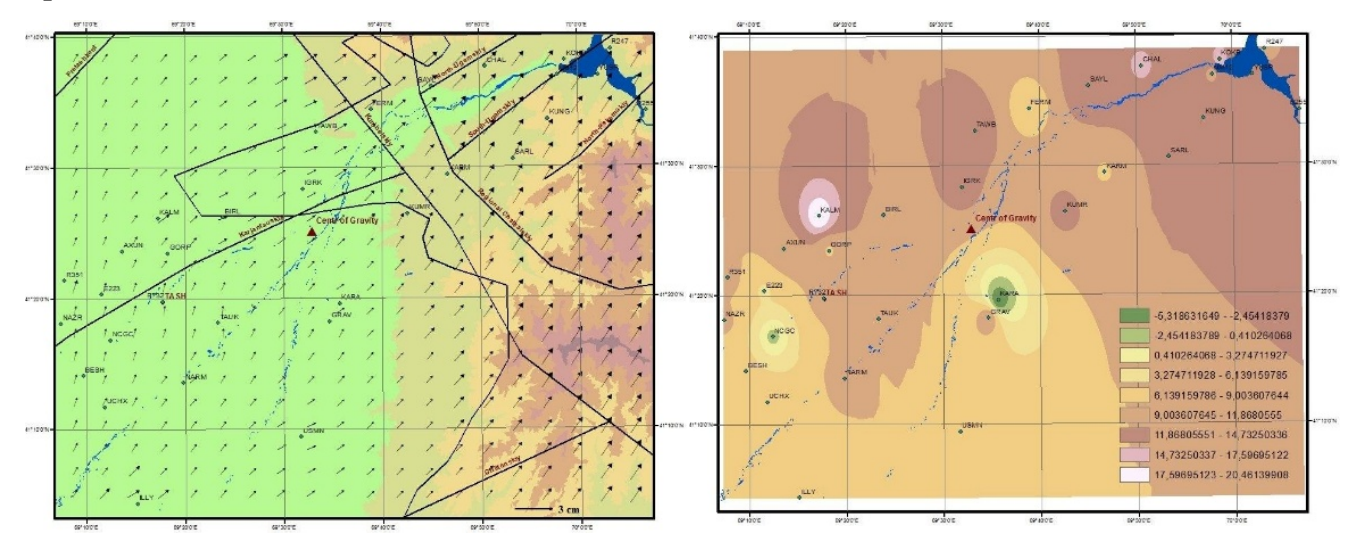

a) b)

Fig.2 Horizontal (a) and vertical (b) deformations of the network during 2009-2011

The result revealed that there are significant horizontal displacements, therefore, it is necessary to estimate the strain accumulation regardless of the datum and the displacement vectors may be used to derive this parameter.

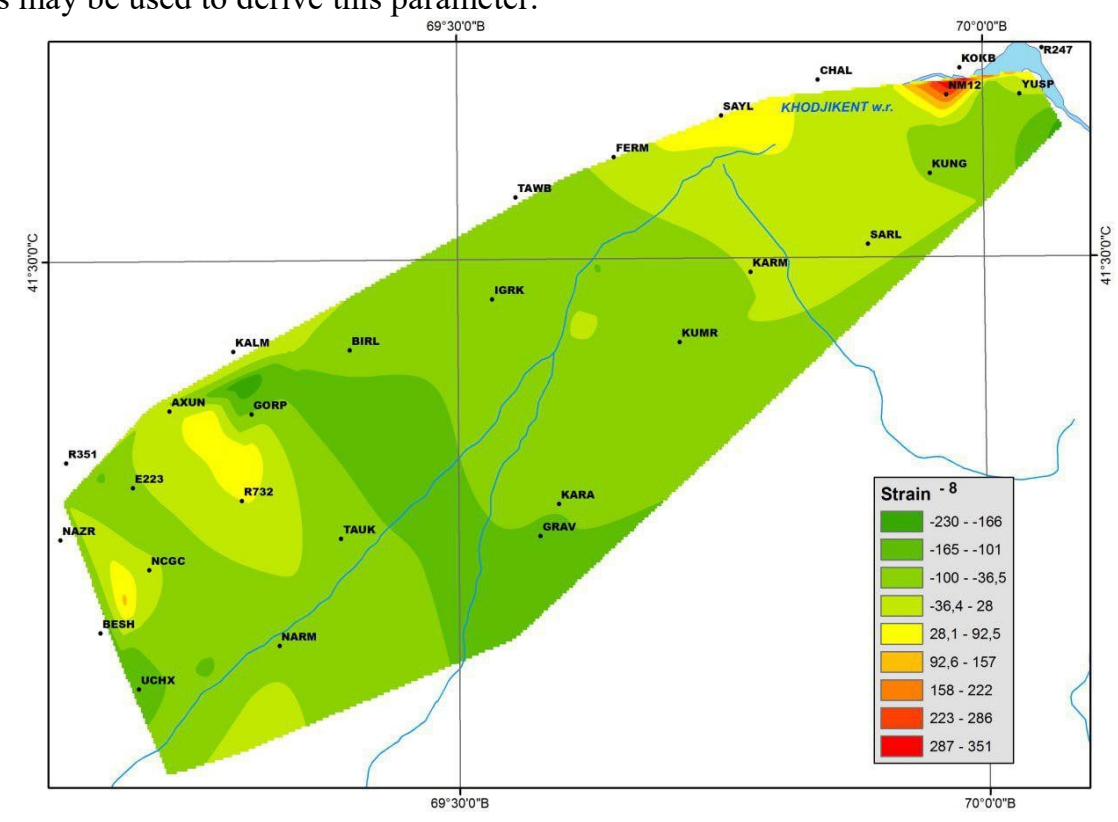

Fig. 3. The map of strain values based on GNSS data over region 
Fig. 3 shows the principal strains rate distribution. Most of the area can be considered to be in a high compression (negative dilatation) strain state. Strain rate for the southwestern part near stations GRAV, KARA, AXUN, GORP as maximum value with $-230 \times 10^{-8}$. Minimum values of extension are found in with a value of $10 \times 10^{-8}$ in flat areas. The results are very similar to the [5]: the strain rate at intersection of active faults Karzhantau, Kumbel and Ugam confirmed $80 \%$ of the value major shear stress caused by the tectonic movements of the whole region. On the contrary, remarkable positive dilatation strain is concentrated on the coastline of the water reservoir, where large strain is about $351 \times 10^{-8}$. The result clear demonstrates that, along strain caused by the tectonic movements, the water level variations in the reservoir is also a major factor determining the displacement and stability of the area.

\section{Conclusions}

The effect of the deformation processes in Tashkent region, was studied by strain deformation calculation with GNSS data. In this regard, as the first step, GNSS stations coordinates were transformed to a datum of the first epoch using the 3D Helmert transformation method, and the horizontal displacement vectors were determined for each station. The result revealed that there are significant horizontal displacements with a maximum value up to $20 \mathrm{~cm}$ in the network and vertical displacements with rates between $5 \mathrm{~cm}$ and $20 \mathrm{~cm}$. The calculation of the network strain was used to assess the network deformation. The network has been constructed of finite elements (triangles) based on the Delaunay triangulation. We found that most of the Tashkent region can be considered to be in a high compression (negative dilatation) strain state confirmed, surely, of the value major shear stress caused by the tectonic movements of the whole region. On the contrary, remarkable positive dilatation strain is concentrated on the coastline of the water reservoir, where large strain is about $351 \times 10^{-8}$. We can conclude that more GNSS campaigns in combination with gravity measurements are needed in this area in order to better constrain the relatively small deformation rates.

This work was carried out within the scientific and applied project FA-Atab-2018-57 of the Astronomical Institute of Uzbekistan with the financial support of the Ministry of Innovative Development of the Republic of Uzbekistan. We are very grateful to Institute of Seismology and National Center of Geodesy and Cartography, who organized GNSS experiments and made the data available to this study.

\section{References}

1. A. R. Yarmukhamedov. The morphostructure of the median Tien Shan and its relationship with seismicity. Tashkent: Fan, 163 (1988) (In Russian). https://www.geofund.am/files/library/1/15247392644395.pdf

2. T. Rashidov, L. Plotnikova and S.Khakimova. Seismic hazard and building vulnerability in Uzbekistan // in Seismic Hazard and Building Vulnerability in PostSoviet Central Asian Republics. edited by S.A. King, Vitaly I. Khalturin, B.E. Tucker. NATO ASI series. Vol.52. (1999)

3. D. Giardini, G. Grünthal, K. M. Shedlock, and P. Zhang. The GSHAP Global Seismic Hazard Map. In: Lee, W., Kanamori, H., Jennings, P. and Kisslinger, C. (eds.): International Handbook of Earthquake \& Engineering Seismology, International Geophysics Series 81 B, Academic Press, Amsterdam, 1233-1239 (2003) http://www.gfz-potsdam.de/GSHAP 
4. T. U. Artikov, R. S. Ibragimov, T. L. Ibragimova, K. I. Kuchkarov, M. A. Mirzaev. Quantitative assessment of seismic hazard for the territory of Uzbekistan according to the estimated maximum ground oscillation rates and their spectral amplitudes. Geodynamics \& Tectonophysics 9 (4), 1173-1188 (2018) doi:10.5800/GT-2018-9-40389.

5. H. L. Hamidov. Identification of morphokinetic indicators of modern geodynamics of western Tiang Shan // Modern geodynamics of Central Asia and dangerous natural processes: quantitative research results: Materials of the All-Russian meeting and youth school on modern geodynamics (Irkutsk, September 23-29, 2012). - In 2-ht. Irkutsk: $\quad$ IZSORAN, $\quad$ T. 211 www.crust.irk.ru/images/upload/newsfond143/299.pdf

(2012)

6. M. Juliev, A. Pulatov, J. Hübl. Natural hazards in mountain regions of Uzbekistan: A review of mass movement processes in Tashkent province. International Journal of Scientific \& Engineering Research, Vol. 8, Issue 2, February (2017)

7. R. P. Wolf, and D. C. Ghilani. Adjustment computations: statistics and least squares in surveying and GIS. Wiley, New York, 347 (1997)

8. I. Deniz, \& H. Ozener. Estimation of strain accumulation of densification network in Northern Marmara Region, Turkey. Natural Hazards and Earth System Science, 10(10), 2135-2143 (2010) https://doi.org/10.5194/nhess-10-2135-2010

9. A. Dermanis. A method for the determination of crustal deformation parameters and their accuracy from distances. J. Geod. Soc. Japan, 40, 17-32 (1994)

10. O.C. Zienkiewicz, R.L. Taylor, and J.Z. Zhu. The Finite Element Method: Its Basis and Fundamentals. 6th edition, Butterworth-Heinemann. 752 (2005)

11. A.O. Agibalov, V.A. Zaytsev, A.A. Sentsov, A.S. Devyatkina. Assessment of the influence of modern crustal movements and the recently activated Precambrian structural plan on the relief of the Lake Ladoga region (the southeastern Baltic Shield). Geodynamics \& Tectonophysics 8 (4), 791-807 (2017) doi:10.5800/GT-2017-8-40317

12. P. D. Dumitru, M. Plopeanu, and D. Badea. Comparative Study Regarding the Methods of Interpolation. In: Proceedings of the 1st European Conference of Geodesy \& Geomatics Engineering (GENG '13), 32-37 (2013) http://www.wseas.us/elibrary/conferences/2013/Antalya/GENG/GENG-00.pdf.

13. D. Fazilova, H. Magdiev. Comparative study of interpolation methods in development of local geoid. International Journal of Geoinformatics, - V.14, №1. 29-33 (2018) http://journals.sfu.ca/ijg/index.php/journal/article/view/1114/599 